\title{
El final de la espiral del caos: \\ la regulación de los actos jurídicos unilaterales de los Estados*
}

\author{
Ending the Spiral of Chaos: \\ Regulation of Unilateral Legal Acts of States
}

\section{Mónica Yamel Naime S. Henkel**}

SUMARIO: I. Introducción. II. La construcción del concepto. III. Validez, modificación y extinción. IV. Fundamento de obligatoriedad. V. La práctica internacional. VI. Conclusión. VII. Bibliografía.

* Artículo recibido el 28 de junio de 2011 y aprobado para publicación el 28 de septiembre de 2011.

** Licenciada en Relaciones Internacionales por la UNAM y en Derecho por el ITAM, con mención honorífica. Actualmente desarrolla su maestría en Derecho Internacional en el Graduate Institute of Internacional and Development Studies (Suiza). 
RESUMEN: En el presente artículo se sostiene la tesis de que no todo lo que comúnmente se considera acto jurídico unilateral del Estado, lo es. Esta conclusión es alcanzada después de un cuidadoso análisis de la práctica internacional y de la refutación de argumentos comúnmente utilizados por los académicos sobre la materia, y por los trabajos de la Comisión de Derecho Internacional, que los llevan a definir al acto jurídico unilateral del Estado de modo muy amplio, incluyendo comportamientos políticos y, en ocasiones, hechos jurídicos.

Palabras clave: acto jurídico unilateral, Estado, obligación internacional, Comisión de Derecho Internacional, Corte Internacional de Justicia, acto político, acto jurídico.

ABSTRACT: This article upholds the thesis that not everything that is commonly considered a unilateral legal act of the State is, in fact, one. This conclusion is reached after a careful analysis of international practice and the rebuttal of the arguments that are usually put forward by scholars on the subject, and the work of the International Law Commission, which leads to define the State's unilateral legal act in a broad sense, including political behaviors and, sometimes, legal facts.

Descriptors: unilateral legal act, State, international obligation, International Law Commission, International Court of Justice, political act, legal act.

RÉSUMÉ: Dans cet article se soutien la thèse que tout ce qui est souvent considéré comme un acte juridique unilatéral de l'État, ne l'est pas. Cette conclusion est atteinte après une analyse minutieuse de la pratique internationale et la réfutation des arguments couramment utilisés par les chercheurs sur le sujet, ainsi que par les travaux de la Commission de Droit International, raisonnements qui conduisent à définir l'acte juridique unilatéral de l'État dans un sens large, y compris le comportement politique et, parfois, les faits juridiques.

Mots clés : acte juridique unilatéral, État, obligation internationale, Commission de Droit Internationale, Court Internationale de Justice, acte politique, acte juridique. 


\section{INTRODUCCIÓN}

El papel del Estado en el concierto internacional es condición sine quae non para la existencia de normas internacionales, ya sea que actúe con otros sujetos internacionales o individualmente. De su actuación conjunta con otros Estados o sujetos de derecho internacional, emanan normas jurídicas derivadas de tratados internacionales, mientras que de su actuación individual se pueden desprender actos jurídicos unilaterales.

El régimen jurídico que regula los tratados es claro. Comprende diversas normas derivadas de acuerdos convencionales, como la Convención de Viena sobre el Derecho de los Tratados, complementada por normas consuetudinarias. La claridad de las normas que forman parte de este régimen jurídico facilita la celebración de tratados, dando mayor seguridad jurídica y estabilidad a las relaciones internacionales.

La doctrina en torno al acto jurídico unilateral, además de ser escasa, es insuficiente para comprenderlo. Hasta la fecha, no hay un régimen jurídico que enmarque las actuaciones unilaterales de los Estados, por lo que se hace imperiosa la necesidad de establecer un régimen jurídico claro que las regule. La falta de nitidez de las normas y su consecuente afectación a la certeza jurídica provoca que un Estado no pueda determinar si tiene o no una obligación unilateral sino hasta el momento en que se le solicita a un tribunal internacional la resolución de un conflicto. El Estado puede entonces tener indeterminadas sus obligaciones en tanto un tribunal las declara como tales.

El interés en los actos jurídicos unilaterales de los Estados surge en 1964 a partir del estudio que les dedica Eric Suy en su tesis doctoral.' Diez años después de su publicación, la Corte Internacional de Justicia retoma el concepto en la sentencia de Ensayos Nucleares, presentándose como el clímax del interés en la materia. Veinticinco años después se retoma el tema con los trabajos elaborados por la Comisión de Derecho Internacional, concluyendo en diez principios generales como guías para la aproximación a estos actos.

Suy, Eric, Les actes juridiques unilatéraux en droit International public, París, Librairie Générale de Droit et Jurisprudence, 1962. 
A pesar del análisis profundo de Suy y de la resolución de la Corte Internacional de Justicia, muchos autores insisten en negarle un papel jurídico a los actos jurídicos unilaterales de los Estados, por carecer del elemento consensual que ellos consideran indispensable para el establecimiento de relaciones jurídicas a nivel internacional. Nuestra postura e hipótesis es la de concebir que estos actos constituyen una fuente de obligación internacional auténtica e independiente de cualquier otro modo de formación normativa internacional, ya que encuentran su fundamento como fuente de obligación autónoma en principios generales del derecho.

La poca claridad teórica implica, en este caso, una confusión en la práctica, ya que o bien se inserta a los actos jurídicos unilaterales dentro de un régimen convencional, o bien se considera que un evento dado, por tener algún elemento de unilateralidad, es un acto jurídico unilateral del Estado, ignorando que subyace una plurilateralidad de fondo. Para evitar esta confusión, en la presente investigación se plantean diversos cuestionamientos: ¿cuál es la definición de acto jurídico unilateral?, ¿qué elementos determinan su validez?, ¿constituye verdaderamente una fuente de obligación internacional?, ¿cuál es su fundamento de obligatoriedad?, y, finalmente, ¿cómo se refleja esto en la práctica?

El propósito del presente estudio será el clarificar el régimen jurídico de los actos jurídicos unilaterales de los Estados, tratando de responder a las interrogantes antes mencionadas, dejando las normas suficientemente claras para que en un momento posterior se pueda emprender un proyecto de articulado o una labor de codificación sin mayor dificultad. Este estudio contribuirá a la seguridad jurídica en el orden internacional y a la certeza en las relaciones internacionales. Para ello, procederemos, por medio de razonamientos inductivo-deductivos, con un análisis del discurso resultante de una búsqueda exhaustiva de textos realizada para este fin.

El que exista un régimen jurídico claro sobre los actos jurídicos unilaterales de los Estados, como el que se propone en el presente estudio, permitiría ampliar el abanico de posibilidades con las que cuenta un Estado para obligarse en el plano internacional, así como también el saber en sentido negativo, cuáles son los actos que debe evitar para no enfrentarse con una exigencia jurídica de su cumplimiento. Esta es la razón de mayor peso sobre la importancia de la presente investigación. 


\section{La definición negativa}

\section{A. Acto político y acto jurídico}

Todo acto realizado por un Estado conlleva implicaciones políticas, al ser ésta su naturaleza intrínseca, pero no todo acto del Estado tiene implicaciones jurídicas. No es fácil trazar la línea de demarcación entre acto político y acto jurídico, sobre todo si consideramos que la distinción nunca es absoluta, pero es una labor que se debe emprender en un estudio jurídico puro del acto jurídico unilateral del Estado.

Un criterio eficaz para distinguir entre actos políticos y jurídicos es con relación a su fundamento, ya que mientras el compromiso político tiene fundamento en la moral, el compromiso jurídico estará fundamentado en una norma jurídica superior. ${ }^{2}$ El criterio que presenta mayor utilidad, sin embargo, es el de considerar que la distinción esencial entre un conflicto jurídico y uno político es el deseo o la intención de los Estados en cuestión de considerarlos o no a la luz del derecho internacional.

La confusión entre lo jurídico y lo político explica en gran parte la reticencia de los Estados a que exista algún instrumento que regule los actos jurídicos unilaterales ya que temen que su campo de acción se vea restringido, al enfrentarse con nuevas e inesperadas obligaciones. Cualquier estudio que analice los actos jurídicos en un nivel internacional debe distinguirlos de los actos políticos.

\section{B. Acto dependiente y acto independiente}

Adoptamos aquí una definición estrecha de "acto jurídico internacional”, dejando fuera de nuestro estudio la definición amplia, que incluye también a aquellos actos que participan en la formación y aplicación del

2 Kelsen, Hans, Teoría pura del derecho, 12a. ed., México, Porrúa, 2002. 
derecho convencional y consuetudinario, ${ }^{3}$ ya que en el presente estudio nos enfocamos a actos jurídicos unilaterales autónomos de cualquier otra fuente de producción normativa. ${ }^{4}$ Rodríguez Cedeño lo pone en las mejores palabras, afirmando que no debe provocar la simple ejecución de una norma aplicable, sino que debe ser el origen de una nueva norma. ${ }^{5}$

El análisis debe ser cauteloso, ya que hay zonas grises: sí estamos frente a un acto unilateral autónomo cuando un Estado manifiesta su voluntad de reconocer como propia una obligación contenida en un tratado, sin que el emisor sea parte del tratado. Se trata de una obligación independiente de la vida del tratado. ${ }^{6}$

Por ejemplo, Suy admite la posibilidad de considerar las declaraciones interpretativas ${ }^{7}$ y las reservas a tratados que no prevén cláusulas

3 Bondia García, David, Régimen jurídico de los actos unilaterales de los Estados, Barcelona, J. M. Bosch Editor, 2004, p. 48: "Si bien la realización del acto unilateral puede venir impuesta o autorizada directamente por el Derecho Internacional General o por normas determinadas, convencionales o consuetudinarias, sólo la validez jurídica de los primeros tiene un fundamento general, de modo que sólo ellos pueden ser considerados verdaderamente autónomos".

4 Para que se considere que un acto jurídico unilateral es una auténtica fuente de obligación internacional, no deben existir condiciones de reciprocidad, sino que el acto se basta a sí mismo para producir efectos jurídicos. Véase Venturini, Gian Carlo, La portée et les effets juridiques des attitudes et des actes unilatéraux des Etats, Recueil des Cours de l'Académie de Droit International, La Haya, 1964, t. 112, p. 400. Véase United States Commission on Ocean Policy, Presidential Proclamation No. 2667, Policy of the United States with respect to the natural resources of the subsoil and sea bed of the continental shelf, http: / / oceancommission.gov/documents/ gov_oceans/truman.pdf, fecha de consulta: 13 de agosto de 2010.

5 Rodríguez Cedeño, “Cuarto informe sobre los actos unilaterales de los Estados”, Documento oficial A/CN.4/519, 30 de mayo de 2001, párr. 38.

6 Como ejemplo tenemos la declaración del representante permanente francés ante la ONU, que declaró el 12 de junio de 1968: "Francia por su lado... se comportará de aquí en adelante en esta materia exactamente como los Estados vinculados por el tratado. No debe quedar duda en nadie en este aspecto" (traducción propia). Con esto asume obligaciones “derivadas" del Tratado de No Proliferación de Armas Nucleares, sin ser parte de él (finalmente se adhirió al tratado en 1992). Véase France TNP 2010, Turning commitments into actions, The NPT: our vital instrument for our collective security, http: / / www.francetnp2010.fr/spip. php?rubrique45, fecha de consulta: 12 de agosto de 2010.

7 Una declaración interpretativa es la declaración hecha por un Estado respecto a su entendimiento de alguna cuestión abarcada por el tratado o su interpretación de una disposición particular, como queda establecido en ONU, Manual de Tratados, Sección de Tratados de la 
expresas sobre esta posibilidad,${ }^{8}$ como una fuente autónoma de obligación. ${ }^{9}$ Sin embargo, consideramos que esto no puede ser posible, debido a que, por un lado, las declaraciones interpretativas quedan reguladas por el derecho de los tratados, esto es, su regulación se deriva no del derecho convencional, sino del derecho consuetudinario internacional. Así, las declaraciones interpretativas quedan sujetas al control de parte del Secretario General de Naciones Unidas, en su calidad de depositario, al ser parte integrante del acta final de cada tratado. Por otro lado, respecto de las reservas, el artículo 19 de la Convención de Viena sobre el Derecho de los Tratados ${ }^{10}$ establece expresamente que una reserva que no esté contemplada en un tratado sólo puede ser realizada si no contraviene el objeto y fin del tratado en cuestión. Con esto, las reservas hechas a un tratado multilateral que no contenga una provisión sobre la materia, quedan reguladas en el derecho convencional y consuetudinario, y no son autónomas en sentido alguno.

\section{Otros conceptos similares: estoppel, aquiescencia y silencio}

Es importante detenernos sobre tres conceptos que tienden a ser incluidos en los estudios sobre actos jurídicos unilaterales de los Estados y que sin embargo son ajenos a él: el estoppel, la aquiescencia y el silencio.

\section{a. Estoppel}

El estoppel es una figura que surge en el derecho privado anglosajón. Si bien es cierto que existe una "familia" de rostros múltiples del esto-

Oficina de Asuntos Jurídicos, 2001, http://untreaty.un.org/English/TreatyHandbookSpan.pdf, fecha de consulta: 24 de agosto de 2010, p. 53.

8 Suy, Eric, op. cit., 2007, pp. 635 y 636: "One may, therefore, ask whether a reservation to a multilateral treaty which does not contain a provision on reservations, should not be considered as a truly autonomous unilateral act, the specific effects of which are solely determined by the declaring party".

9 Suy, Eric, op. cit., 2007, p. 635. "But authentic interpretative declarations could very well be considered as genuine autonomous unilateral acts generating the legal effects intended by the author."

10 ONU, "Convención de Viena sobre el Derecho de los Tratados", Viena, Austria, 23 de mayo de 1969, Diario Oficial de la Federación, 14 de febrero de 1975. 
ppel, ${ }^{11}$ el sentido más estricto es el que lo entiende como una regla procesal (rule of evidence) en virtud de la cual una parte de un litigio no está habilitada a modificar el valor de los hechos que ha realizado aportando pruebas en contrario, para tratar de establecer una verdad diferente, causando con ello un perjuicio a su contraparte. ${ }^{12}$ Ya Nöcker admite un problema en la aplicación de esta figura en el derecho público interno, ${ }^{13}$ por lo que su transposición al derecho internacional público es aún más discutible.

Para clarificar, vale la pena citar dos ejemplos ante la Corte Internacional de Justicia:

1) En la sentencia dictada el 15 de junio de 1962 en el caso del Templo de Preah Vihear, ${ }^{14}$ la Corte consideró que Tailandia, por el principio de estoppel, no podía negar ser parte en una Convención de 1904 sobre fronteras cuando durante mucho tiempo invocó y disfrutó los beneficios del acuerdo.

2) En la sentencia del 13 de diciembre de 2007 en Nicaragua c. Colombia, ${ }^{15}$ la Corte estimó que Nicaragua, por el principio del estoppel, había perdido el derecho a negar la validez de un tratado concluido con Colombia en 1928 cuya vigencia había reconocido durante más de cincuenta años.

1 Véase Fauvarque-Cosson, Bénédicte, "La confiance légitime et l'estoppel: rapport général”, La confiance légitime et l'estoppel, París, Société de Legislation Comparée, 2007, pp. 9-61. El estoppel es considerado un principio sólo en materia de arbitraje comercial internacional, mas no en derecho internacional en general, en donde se aplica con extrema caución.

12 Salmon, Jean, Dictionnaire de droit international public, Bruselas, Bruylant, 2001, p. 450.

13 Nocker, Thomas y French, Gregory, “Estoppel: What's the Government's Word Worth? An Analysis of German Law, Common Law Jurisdictions, and of the Practice of International Arbitral Tribunals”, The International Lawyer, ABA, Washington DC, 1990, vol. 24, núm. 2, p. 412: "Although the courts have developed a doctrine of equitable estoppels... the doctrine of equitable estoppel does not apply to the government”.

14 Temple of PreahVihear (Cambodia c. Tailandia), fondo del asunto, ICJ Reports 1962, sentencia del 15 de junio de 1962, pp. 30 y ss.

15 Territorial and maritime dispute (Nicaragua c. Colombia), excepciones preliminares, ICJ Reports 2007, sentencia del 13 de diciembre de 2007. 
Esta misma Corte ya ha afirmado que el estoppel tiene aplicación sólo dentro de un procedimiento judicial. ${ }^{16}$ Este principio, por lo tanto, puede ser utilizado como un chaleco antibalas (medio de defensa) pero no como una pistola (fundamento de una acción). El estoppel impide que un Estado se retracte de una actitud anterior.

En este sentido, sus efectos son los mismos que los del acto jurídico unilateral. ${ }^{17}$ La misma Corte ya ha dicho que el estoppel no es sólo este efecto, sino que para poder alegar que un Estado está impedido bajo esta figura, es necesario que los terceros se hayan fundado en el comportamiento del Estado, lo que los llevó a modificar su posición en su detrimento. ${ }^{18}$ El origen de la obligación está en distintos lugares para el estoppel y para el acto jurídico unilateral. En el primer caso, es la confianza en terceros, y en el segundo caso, es la intención del autor.

\section{b. Aquiescencia y silencio}

Entendemos por "silencio" la inacción o comportamiento que tiene un efecto de aquiescencia o de reconocimiento. ${ }^{19} \mathrm{Y}$ por aquiescencia, el consentimiento derivado de las conductas pasivas de un Estado frente a una situación determinada. ${ }^{20}$ Realizamos un análisis conjunto ya que ambos se originan en la inactividad del Estado.

A pesar de que el silencio y la aquiescencia guardan una estrecha relación con figuras típicamente consideradas actos jurídicos unilaterales estatales, como la protesta o el reconocimiento, e incluso la renuncia, estas figuras no serán consideradas en este estudio como un acto jurídico unilateral, debido a que implican un acuerdo de voluntades, derivados del consentimiento tácito, insertándose en un marco convencional y no unilateral.

16 Barcelona Traction (Bélgica c. España), excepciones preliminares, ICJ Reports 1964, sentencia del 24 de julio de 1964, p. 24.

17 Jacqué, Jean-Paul, “A propos de la promesse unilaterale”, Mélanges offerts à Paul Reuter: le droit international: unité et diversité, París, Pedone, 1981, pp. 336-337.

18 Temple of Preah Vihear (Cambodia c. Tailandia), opinión individual del juez Sir Gerald Fitzmaurice, ICJ Reports 1962, sentencia del 15 de junio de 1962, p. 63.

19 Salmon, Jean, Dictionnaire de droit international public, Bruselas, Bruylant, 2001, p. 1035.

20 Ibidem, p. 21. 
No se niega que en determinadas circunstancias estas produzcan efectos jurídicos, pero no son estos "actos" los que están al origen de una obligación, sino la conducta ante la cual se omite actuar y el deducido acuerdo de voluntades. Claramente expuesto por Rodríguez Cedeño: "Es siempre un comportamiento reactivo, relacionado con un acto u otro comportamiento preexistente, lo que le ubica en la relación convencional". ${ }^{21}$

\section{La definición positiva: elementos constitutivos de los actos unilaterales estatales}

En derecho internacional, es palpable la permeabilidad que se tiene con el derecho privado. Como lo señala Del Castillo: "El concepto de acto jurídico fue ajeno a la doctrina del Derecho Internacional mientras no se insinuaron vasos comunicantes con el Derecho Privado, que comenzaron a impregnar este concepto en la teoría clásica de las fuentes”. ${ }^{22}$

Entendemos, por "acto jurídico" la actividad humana que tiene como efecto la modificación del orden jurídico en razón de que dicha actividad se realiza justamente con la intención de producir esos efectos. Un acto jurídico internacional sería entonces aquella actividad de un sujeto del derecho internacional que tiene como efecto la modificación del orden jurídico internacional, en razón de que dicha actividad se realiza justamente con la intención de producir esos efectos.

Al calificar el acto jurídico de "unilateral", implica que se trata de una sola manifestación de voluntad, es decir, la voluntad que emana de un solo sujeto de derecho. No se excluye con esto el estudio de actos colectivos, entendidos estos como una manifestación de voluntad única proveniente de una pluralidad de sujetos. Esto puede ser el caso en que

21 Rodríguez Cedeño, Víctor y Guerrero Peniche, Nicolás, "Los actos unilaterales de los Estados en derecho internacional: los trabajos de codificación de la Comisión de Derecho Internacional”, Anuario Mexicano de Derecho Internacional, vol. III, 2003, http: / / www.bibliojuridica. org/estrev/derint/cont/3/art/art7.htm, fecha de consulta: 5 de octubre de 2010.

22 Castillo, Lilian del, "Comentarios sobre el derecho internacional de los actos jurídicos unilaterales”, Estudios de derecho internacional en homenaje del profesor Ernesto J. Rey Caro, Córdoba, Lerner, vol. 1, 2002, pp. 52 y 53. 
diversos Estados realicen conjuntamente un acto unilateral, asumiendo ellos —y sólo ellos — las obligaciones derivadas.

No negamos la posibilidad de que algunos actos jurídicos internos se constituyan como productores de efectos jurídicos en el plano internacional, como la determinación de la extensión territorial, o una ley sobre nacionalidad, dado que estos actos jurídicos crean situaciones jurídicas que son oponibles conforme al derecho internacional. Pero no dejan de ser, para el orden internacional, hechos jurídicos ${ }^{23}$ que tienen consecuencias jurídicas en el plano internacional, independientemente de si éstas hayan sido o no deseadas.

Se define al acto jurídico unilateral del Estado como aquella actividad individual y autónoma de un Estado, que tiene como efecto la modificación de su patrimonio jurídico internacional, en razón de que dicha actividad se realiza justamente con la intención de producir esos efectos.

\section{VALIDEZ, MODIFICACIÓN Y EXTINCIÓN}

\section{Requisitos de validez}

Si un Estado contrae obligaciones como resultado de cada acción, declaración o conducta, la practica estatal se vería seriamente limitada y el sistema internacional paralizado. ${ }^{24}$ Afortunadamente, no cualquier manifestación de voluntad produce efectos jurídicos, sino que es nece-

23 Suy, Eric, "Unilateral acts of States as a Source of International Law: Some New Thoughts and Frustrations", Droit du pouvoir, pouvoir du droit: mélanges offerts a Jean Salmon, Bruselas, Bruylant, 2007, p. 632; Miaja de la Muela, Adolfo, "Los actos unilaterales en las relaciones internacionales", Revista Española de Derecho Internacional, Madrid, Instituto Francisco de Vitoria, 1967, vol. 20, p. 452: "Las leyes internas, en cuanto expresión de la voluntad y de la actividad del Estado, lo mismo que sus resoluciones judiciales o sus actos administrativos, constituyen ante el Derecho Internacional meros hechos, susceptibles de calificarse como lícitos según su conformidad o discrepancia con el Derecho Internacional”.

${ }^{24}$ Goodman, Camille, “Acta Sunt Servanda?: a Regime for Regulating the Unilateral Acts of States at International Law”, The Australian Yearbook of International Law: annual Surrey of Current Problems of Public and Private International Law with a Digest of Australian Practice, Sydney, Butterworths, vol. 24, 2004, p. 53. 
sario que el acto satisfaga ciertos requisitos de validez. Estos requisitos, que analizaremos a continuación, son: sujeto capaz, objeto apropiado, intención requerida, y forma correcta.

\section{A. Sujeto capaz}

Para que un comportamiento sea atribuible al Estado, éste debe emanar de un órgano competente para obligarlo. ${ }^{25}$ En este sentido, la Convención de Viena sobre el Derecho de los Tratados es la base para determinar qué personas pueden obligar al Estado en la esfera internacional, ${ }^{26}$ es decir, el jefe de Estado, jefe de gobierno, ministros de relaciones exteriores, y jefes de misión diplomática dentro de la esfera de su competencia.

Resulta tentador el tratar de hacer referencia a la Convención sobre Responsabilidad del Estado por Hechos Internacionalmente Ilícitos como guía para determinar los sujetos capaces de comprometer al Estado, pero aquí no lo consideramos correcto, debido a una razón fundamental: la distinción entre hecho y acto jurídico. Un hecho jurídico lo produce un sujeto, con independencia de su voluntad, ya que las consecuencias se producen por ministerio de ley; pero en un acto, la voluntad es esencial para la producción de efectos, por lo que el sujeto que lo realiza debe estar calificado para que su voluntad genere tales efectos.

El relator especial ${ }^{27}$ también incluyó "otras personas que representan al Estado en esferas determinadas... en las materias que correspondan a su esfera de competencia”. ${ }^{28}$ Consideramos que esta adición del Relator es muy oportuna, dado que refleja la práctica estatal actual, en la que

25 Artículo 4o. del proyecto de Convención sobre Responsabilidad del Estado por Hechos Internacionalmente Ilícitos, adoptado por la Comisión de Derecho Internacional a la Asamblea General en 2001, en http://untreaty.un.org/ilc/texts/instruments/english/draft\%20 articles 19_6_2001.pdf.

26 Artículo 7o. de la Convención de Viena sobre el Derecho de los Tratados.

27 En 1997, la CDI estableció un Grupo de Trabajo y nombró un relator especial, el venezolano Víctor Rodríguez Cedeño, para estudiar la cuestión de los actos unilaterales de los Estados.

28 Asamblea General de la ONU, "Principios rectores aplicables a las declaraciones unilaterales de los Estados capaces de crear obligaciones jurídicas”, Anuario de la CDI, Documento oficial A/61/10, 2006, vol. II, Parte 2, p. 407. 
las competencias de los funcionarios de un gobierno son cada vez más internacionalizadas. En palabras más claras, en una reciente sentencia de la Corte Internacional de Justicia:

Es cada vez más frecuente en las relaciones internacionales modernas que otras personas que representan a un Estado en determinados ámbitos sean autorizadas por dicho Estado para obligarlo mediante sus declaraciones en las materias de su competencia. Este puede ser el caso, por ejemplo, de los titulares de carteras ministeriales técnicas que ejerzan, en las relaciones exteriores, poderes que estén dentro de su esfera de competencia, e incluso de determinados funcionarios. ${ }^{29}$

Como posibilidad remota, si se cae dentro del caso de que una persona no habilitada por el Estado formula un acto unilateral, o una persona habilitada actúa ultra vires, ${ }^{30}$ son aplicables las normas del Convención de Viena sobre el derecho de los tratados ${ }^{31}$ en el sentido de que para que surta efectos dicho acto es necesario que el Estado ulteriormente reconozca dicha actuación como propia. Esta Convención es aplicable para este caso concreto, debido a que no se trata de una disposición exclusiva sobre obligaciones convencionales, sino que es para cualquier tipo de obligación, sea cual fuere su origen, ya sea convencional, consuetudinaria o unilateral.

\section{B. Objeto apropiado}

Como en derecho civil, ${ }^{32}$ si el objeto de un acto jurídico unilateral consiste en una obligación de dar, el objeto del acto jurídico unilateral debe: existir en la naturaleza; ser determinado o determinable, y estar en el comercio. En el caso de que se trate de una obligación de hacer o no

29 Armed Activities on the Territories of the Congo (New Application: 2002) (República democrática del Congo c. Ruanda), competencia y admisibilidad, ICJ Reports 2006, sentencia del 3 de febrero de 2006, párr. 47.

30 Ya sea fuera de sus competencias, o en contradicción con sus instrucciones.

31 Artículo 8o. de la Convención de Viena sobre el Derecho de los Tratados.

32 Rico Álvarez, Fausto y Garza Bandala, Patricio, Teoría general de las obligaciones, 2a. ed., México, Porrúa, 2006, pp. 90 y 91. 
hacer, el objeto de dicho acto debe ser: posible tanto física como jurídicamente, y lícito.

La licitud del objeto debe estar acompañada de la licitud en el fin, ya que si por medio del acto jurídico unilateral el Estado busca eludir una obligación internacional, entonces éste no podría tener validez alguna. Asimismo, es importante enfatizar en que el objeto debe ser concreto y preciso. Esta condición tiene numerosos respaldos por la Corte Internacional de Justicia. Primeramente afirma que "es bien reconocido que actos unilaterales hechos por declaraciones, sobre situaciones fácticas o jurídicas, pueden tener el efecto de crear obligaciones jurídicas. Declaraciones de este tipo pueden ser, y frecuentemente son, muy específicas", ${ }^{33} \mathrm{y}$ en segundo lugar, también sostiene que "el objeto de estas afirmaciones es claro y dirigido a la comunidad internacional en su conjunto, y la Corte sostiene que constituyen un compromiso con efectos jurídicos". ${ }^{34}$

Goodman sostiene que "el objeto de un acto unilateral no debe estar en conflicto con otra obligación internacional contraída por el Estado, ya que de lo contrario acarrearía la responsabilidad internacional del Estado". ${ }^{35}$ Esto implica una jerarquía normativa en la que los actos unilaterales estarían subordinados a otros modos de producción normativa, sean estos convencionales o consuetudinarios, pero si los actos unilaterales son normas independientes, entonces su validez únicamente queda sujeta a que el objeto no sea contrario a normas imperativas de derecho internacional.

Es inevitable, sin embargo, que existan conflictos entre normas unilaterales y normas convencionales o consuetudinarias, pero debe ser resuelto atendiendo primordialmente a un criterio material, lex specialis,

33 Nuclear tests, op. cit., párr. 43, traducción propia, en inglés: It is well recognized that declarations made by way of unilateral acts, concerning legal or factual situations, may have the effect of creating legal obligations. Declarations of this kind may be, and often are, very specific.

34 Ibidem, párr. 51, traducción propia, en inglés: The objects of these statements are clear and they were addressed to the international community as a whole, and the Court holds that they constitute an undertaking possessing legal effect.

35 Goodman, Camille, op. cit., p. 55, traducción propia, en inglés: The object of a unilateral act should not conflict with that of another international engagement contracted by the state, or it may attract the international responsibility of the state. 
que prevalece sobre normas generales. Si es imposible resolver con el criterio de especialidad, el conflicto se resuelve como si fuera un conflicto entre tratados contradictorios, ${ }^{36}$ es decir, la obligación unilateral prevalecerá sólo en tanto no se esté violando la obligación convencional respecto de los Estados parte de ese tratado. ${ }^{37}$ En ningún caso se prejuzga sobre la responsabilidad internacional en la que puede recaer el Estado emisor.

\section{Intención requerida}

La voluntad del Estado es un elemento central, ya que no es cualquier declaración o manifestación unilateral la que obliga al Estado internacionalmente. Entendemos por "intención” la voluntad claramente expresada por el autor.

En primer lugar, no basta que el Estado anuncie el comportamiento que considera realizar, sino que tenga el deseo de imponerse una conducta jurídicamente obligatoria. ${ }^{38}$ Nos debemos referir a la sentencia de Ensayos nucleares, ya que es en la que la Corte Internacional de Justicia de modo claro hace hincapié en este elemento como elemento para la eficacia del acto jurídico unilateral:

Cuando es la intención del Estado que realiza la declaración el quedar vinculado según sus propios términos, esa intención confiere a la declaración el carácter de un compromiso jurídico, por lo que el Estado subsecuentemente estaría jurídicamente requerido a seguir un rumbo de conductas consistentes con la declaración. ${ }^{39}$

36 Jacqué, Jean-Paul, “A propos de la promesse unilatérale”, Mélanges offerts à Paul Reuter: le droit international: unité et diversité, París, Pedone, 1981, pp. 334 y 335: Quant au conflit entre un acte unilatéral et un traité, il ne se règle pas plus facilement qu'un conflit entre traités contradictoires.

37 Artículo 30 de la Convención de Viena sobre el Derecho de los Tratados.

38 Charpentier, Jean, "Engagements unilatéraux et engagements conventionnels: différences et convergences", Theory of International Law at the Threshold of the 21st Century: Essays in Honor of Krzysztof Skubiszewski, La Haya, Kluwer Law International, 1991, p. 372.

39 Nuclear tests, op. cit., párrs. 43 y 44, traducción propia, en inglés: When it is the intention of the State making the declaration that it should become bound according to its terms, that intention confers on the declaration the character of a legal undertaking, the State being 
En segundo lugar, la intención debe ser manifestada claramente para que tenga eficacia jurídica, ya que no se puede presumir una limitación a la soberanía estatal, ${ }^{40}$ aunque su fuente sea unilateral. Si no es clara la intención del autor del acto unilateral de quedar vinculado jurídicamente, es posible recurrir a la figura de estoppel que ya analizamos.

Como ejemplo de cómo la Corte Internacional de Justicia ha interpretado la intención del Estado de quedar obligado unilateralmente, tenemos el caso de Actividades militares y paramilitares, en el cual la Corte concluyó que las declaraciones hechas por el gobierno nicaragüense respecto del compromiso de llevar a cabo elecciones democráticas dentro de cierto plazo, eran declaraciones políticas y desprovistas de fuerza jurídica. ${ }^{41}$ No debemos ver aquí, como lo hace Rodríguez y Torres, que "el estudio y la consideración por los tribunales de este tema no ha conducido siempre a la misma conclusión”. ${ }^{42}$ Más bien, en el caso antes mencionado, Nicaragua especifica en sus declaraciones que estas solo tendrán efecto en el orden interno, ${ }^{43}$ por lo que se puede desprender una intención clara de no quedar obligado en el plano internacional, no

thenceforth legally required to follow a course of conduct consistent with the declaration. An undertaking of this kind, if given... with an intent to be bound... is binding... Of course, not al1 unilateral acts imply obligation; but a State may choose to take up a certain position in relation to a particular matter with the intention of being bound.

40 Lotus case (Francia c. Turquía), CPIJ, Serie A, núm. 10, sentencia del 7 de septiembre de 1927, p. 18.

${ }^{41}$ Military and Paramilitary Activities in and against Nicaragua (Nicaragua c. Estados Unidos de América), fondo del asunto, ICJ Reports 1986, sentencia del 27 de junio de 1986, párr. 257262. Véase párr. 261: "Nor can the Court take the view that Nicaragua actually undertook a commitment to organize free elections, and that this commitment was of a legal nature... But the Court cannot find an instrument with legal force, whether unilateral or synallagmatic, whereby Nicaragua has committed itself in respect of the principle or methods of holding elections".

42 Rodríguez Cedeño, Víctor y Torres Cazorla, Ma. Isabel, "Contribución al estudio de los actos unilaterales de los Estados: ¿una labor de codificación posible?”, Liber amicorum en homenaje al profesor Dr. Didier Opertti Badan, Montevideo, Fundación Cultura Universitaria, 2005 , p. 762.

43 Military and Paramilitary Activities in and against Nicaragua, cit., párr. 261: The resolution of 23 June 1979 also declares that the solution of their problems is a matter "exclusively" for the Nicaraguan people, while stating that that solution was to be based (in Spanish: debería inspirarse) on certain foundations which were put forward merely as recommendations to the future government. 
pudiéndose interpretar más allá de la expresión de voluntad, por más beneficioso que pueda ser para la comunidad internacional el ampliar la obligación.

\section{Forma y publicidad}

Respecto a la forma que debe revestir el acto, no hay ninguna regla restrictiva. Sólo se requiere la manifestación explícita ${ }^{44}$ de la intención a fin de garantizar la certeza y la seguridad en las relaciones internacionales. No importa si se hace de modo escrito u oral ya que,

ya sea que una declaración se realice de modo oral u escrito no hace una diferencia esencial, ya que estas declaraciones hechas en circunstancias particulares pueden crear compromisos en Derecho Internacional, el cual no requiere que sea expresado en forma escrita. Por lo tanto, la cuestión de la forma no es decisiva. ${ }^{45}$

Por su lado, en su segundo informe, el relator especial establece que la publicidad es un elemento constitutivo del acto unilateral estatal, sin la cual está desprovisto de valor jurídico cualquiera. ${ }^{46}$ Desde nuestra percepción, partiendo del hecho de que el destinatario no participa en la elaboración del acto — característica derivada de la unilateralidad_-, y que tampoco es necesario que preste su consentimiento

44 Sellares afirma que "los actos unilaterales no sólo son orales o escritos, sino que también pueden resultar de lenguaje corporal”, en cuyo caso también los zapatazos que dio Krutchev en la Asamblea General en 1960, como reacción a la acusación del delegado filipino de que la URSS implantaba imperialismo en Europa del Este, constituirán un tipo de acto jurídico unilateral. Por razones de coherencia, de seguridad jurídica, de practicidad e incluso de diversidad cultural, este argumento debe ser desechado. Véase Sellarés Serra, Jordi, Applause as a Unilateral Act (Is an image worth a thousand words?), European Society of International Law, 2006, http://www.esil-sedi.eu/publi_search.php, fecha de consulta: 26 de noviembre de 2010, p. 2, traducción propia, en inglés: unilateral acts are not just oral or written but can also be in body language.

45 Nuclear tests, op. cit., párr. 45, traducción propia, en inglés: Whether a statement is made orally or in writing makes no essential difference, for such statements made in particular circumstances may create commitments in international law, which does not require that they should be couched in written form. Thus the question of form is not decisive.

46 Rodríguez Cedeño, "Segundo informe sobre los actos unilaterales de los Estados", Documento oficial A/CN.4/500, 14 de abril de 1999, párrs. 54-56. 
- característica derivada de la autonomía-, no puede considerarse la publicidad como elemento constitutivo, que sí en materia de tratados, cuyo proceso de celebración excluye la posibilidad de que una parte ignore su existencia.

Que un Estado no conozca la existencia de un acto jurídico unilateral del cual éste se podría beneficiar no le resta valor jurídico al acto. La publicidad, por tanto, sólo es un indicio importante en cuanto a la voluntad de asumir una obligación internacional, pero no indispensable. Que no se entienda que estamos admitiendo la posibilidad de considerar a un Estado obligado en el caso en que el jefe de Estado realice una promesa en su oficina particular, y sin testigo alguno.

Lo que es necesario es que haya una exteriorización mínima de la manifestación de voluntad. Con esto implicamos que el acto jurídico pueda ser conocido, por lo menos, por otro sujeto de derecho internacional. El acto jurídico unilateral del Estado estaría adquiriendo su forma definitiva, inspirando confianza en la legitimidad del acto a otros sujetos internacionales, evitando que el Estado emisor modifique el acto como le venga en gana.

\section{Modificación y extinción}

La cuestión de la modificación de los actos jurídicos unilaterales es fácil de tratar. Si la modificación consiste en aumentar las obligaciones unilaterales a cargo del emisor, entonces se analiza como la emisión de un nuevo acto unilateral, con todas las implicaciones vistas anteriormente. En cambio, si se trata de disminuir las obligaciones contenidas en el acto, entonces es aplicable lo que diremos a continuación sobre la revocación de estos actos, seguido de la emisión de un nuevo acto unilateral.

Es cierto que debe existir la posibilidad de revocar o dar por terminada la obligación derivada de un acto unilateral ya que, de lo contrario, el Estado emisor estaría obligado ad perpetuam, sin posibilidad de modificar su comportamiento — so pena de caer en responsabilidad internacional-

D’Aspermont parte de la presunción de que los actos unilaterales son no revocables a menos que medie el consentimiento del Estado que se 
beneficia de dicha obligación. ${ }^{47} \mathrm{Si}$ el destinatario del acto jurídico unilateral es la comunidad internacional en su conjunto, ¿se presume su consentimiento?, o ¿debe ir el Estado emisor, sujeto por sujeto solicitando su consentimiento para revocarla? Más bien se trataría de la extinción de una obligación por condonación.

Quoc Dinh se libera del problema diciendo que para revocar las obligaciones derivadas de los actos unilaterales se debe recurrir a los procesos habituales de la solución pacífica de controversia..$^{48}$ Pero es esto justamente lo que se busca evitar con las labores de codificación en esta materia, es decir, si se deja a los tribunales internacionales la búsqueda de la existencia o inexistencia de una obligación, los Estados no podrían saber de antemano a qué regulación quedan sometidos sus actos jurídicos unilaterales.

La cuestión se encuentra en analizar bajo qué condiciones y con qué garantías puede ser revocado por el Estado un acto jurídico unilateral para que éste no pueda considerarse arbitraria. ${ }^{49}$ Juzgamos que si en la misma manifestación de voluntad se precisa la intención de que el acto sea revocable, entonces el acto es revocable con las limitaciones impuestas en la misma manifestación de voluntad — condicionado, claro está, a que dicha obligación no adquiera la cualidad de potestativa- - Si, al contrario, al emitirlo se precisa la voluntad de que el acto sea irrevocable, entonces no debe ser revocable prima facie..$^{50}$

47 D’Aspermont Lynden, Jean, "Les travaux de la Commission de Droit International relatifs aux actes unilatéraux des Etats”, Revue générale de Droit International Public, París, Pedone, vol. 109 , fasc. 1,2005 , p. 188.

48 Quoc Dinh, Nguyen, Droit International Public, 5a. ed., París, Librairie Générale de Droit et de Jurisprudence, 1994, p. 358.

49 Nuclear tests, op.cit., párr. 51: "The Court finds that the unilateral undertaking resulting from these statements cannot be interpreted as having been made in implicit reliance on an arbitrary power of reconsideration". Se debe atener — de modo enunciativo- a: 1) los términos de la declaración que se refieran específicamente a la revocación; 2) la medida en que los sujetos a quienes se deba el cumplimiento de las obligaciones se hayan basado en ellas, y 3) la medida en que se ha producido un cambio fundamental en las circunstancias. Véase Asamblea General de la ONU, "Principios rectores aplicables a las declaraciones unilaterales de los Estados capaces de crear obligaciones jurídicas”, Anuario de la CDI, Documento oficial A/61/10, 2006, vol. II, parte 2, p. 421.

50 Siempre queda la posibilidad de revocar el acto por un cambio fundamental de circunstancias, tal como lo establece la norma consuetudinaria cristalizada en el artículo 62 de la Convención de Viena sobre el derecho de los tratados. 
Charpentier afirma que es una cuestión meramente teórica, ya que quienquiera que revoque un acto unilateral, quedará totalmente marginado de la comunidad internacional. ${ }^{51}$ Esta es una conclusión a la que llega sin fundamentación, y debemos rechazarla, sobre todo ya que es muy fácil imaginar la situación contraria en la que

una declaración [tenga] un compromiso limitado en el tiempo, por ejemplo, una acción de cooperación traducida en el hipotético caso del compromiso de enviar personal técnico por un tiempo a otro Estado. Una ayuda o una acción de cooperación temporal. ${ }^{52}$

Por lo que en ciertos casos, hasta sería recomendable que el acto unilateral fuera revocable y es nuestra creencia que la comunidad internacional agradecería este tipo de compromisos.

Proponemos intentar hacer aplicables las normas sobre libertad de revocación que surte efectos con cierto plazo de modo análogo a la denuncia de un tratado. ${ }^{53}$ No hay razones por las que se podría considerar inoportuna una regla que establezca que un Estado deba notificar con doce meses de anticipación su intención de revocar el acto jurídico unilateral para que pueda tener efectos dicha revocación.

Por último, deseamos precisar que por analogía con el principio establecido en el artículo 70, inciso 1b, de la Convención de Viena sobre el Derecho de los Tratados, que parece resultar aplicable, la terminación de un acto jurídico unilateral no afecta ningún derecho, obligación o situación jurídica creada entre el emisor y beneficiarios que se haya creado por la ejecución del acto antes de su terminación.

51 Idem.

52 Rodríguez Cedeño, Víctor, "De la interpretación y revocación de los actos unilaterales en sentido estricto”, Anuario Colombiano de Derecho Internacional, Bogotá, año I, núm. 1, 2008, p. 102 .

53 Artículo 56 de la Convención de Viena sobre el Derecho de los Tratados. 
Existen dos posiciones antagónicas en este aspecto: las que son escépticas respecto de la relevancia de analizar el fundamento de estos actos, y las que afirman que sí es relevante.

\section{Postura de los escépticos}

Encontramos básicamente cinco diferentes posicionamientos que niegan la relevancia del estudio del fundamento de obligatoriedad de los actos jurídicos unilaterales. Todos ellos pueden ser rebatidos, como quedará demostrado a continuación:

1) Que el asunto no es importante: es una aproximación pragmática. Se parte del supuesto que la norma está fundamentada, dado que existe. Pero consideramos que no se trata aquí de un "si existe, entonces está fundamentado", ${ }^{54}$ sino de un descartiano "si está fundamentado, entonces existe".

2) Que considerar a dichos actos como fuente de obligación, sea cual fuere su fundamento, es algo superficial: postura principalmente sostenida por Brownlie, que afirma que si estos actos son o no vinculantes, dependerá del contexto en el que una "promesa" o "protesta" sea realizada, incluyendo las circunstancias del acto. ${ }^{55}$ Por lo tanto, Brownlie remite a un análisis casuístico, sin posibilidad alguna de establecer reglas generales. No se debe bajar los brazos

${ }^{54}$ Schachter claramente afirma que "el jurista internacional práctico no debe estar consternado por el fundamento de la obligación, sino por las llamadas fuentes, formales y materiales", véase Schachter, Oscar, “Towards a theory of international obligation”, Schweizerisches Jahrbuch für internationales Rechts, Zürich, vol. 37, 1981, p. 10, traducción propia, en inglés: The practical international lawyer is supposed to be concerned not with the foundation of obligation but with the so-called "sources", formal and material.

55 Brownlie, Ian, Principles of Public International Law, 6a. ed., Nueva York, Oxford, 2003, pp. 612 y 613 . 
ante dicha labor, vale la pena tratar de intuir reglas generales que, por lo menos, tendrán el efecto de contribuir en la doctrina.

3) Que dichos actos carecen de fundamento a menos que una norma convencional así lo disponga: esto sería lo sostenido por la teoría voluntarista, ${ }^{56}$ insertándolos así dentro de un régimen convencional, y no uno autónomo, como se propone en el presente estudio.

4) Que no son una fuente de derecho ni de obligaciones: esta teoría se basa en lo estrictamente establecido en el artículo 38 del Estatuto de la Corte Internacional de Justicia, siendo Jennings su más alto expositor. Este autor hace un análisis sobre fuentes "futuras" que deben ser adicionadas a dicho artículo, pero no incluye a los actos unilaterales aquí estudiados. ${ }^{57}$ Sólo podemos deducir que rechaza implícitamente que los actos jurídicos unilaterales de los Estados son fuentes de obligación.

5) Que un Estado nunca realizará un acto que le genere una obligación unilateral: esta teoría parte del supuesto de que al ser el orden jurídico internacional un sistema horizontal no jerarquizado, los sujetos preferirán siempre la negociación y autointerpretación a la certeza. ${ }^{58}$ Es la postura sostenida por Rubin, el más resistente a considerar a estos actos como cualquier tipo de fuente de obligación. Surgen dos objeciones: primero, es cierto que el sistema internacional no tiene una estructura jerárquica tan clara como los sistemas nacionales, pero en la actualidad es difícil sostener que carezca absolutamente de jerarquía, sobre todo si consideramos las normas de ius cogens. Segundo, no es necesariamente verdadero que en todos los casos sea preferible la negociación a una obligación autoimpuesta, la libertad de acción corresponde al Estado.

56 Doctrina jurídica según la cual el derecho internacional está fundado sobre la voluntad de los Estados. Consideramos que el voluntarismo implica cierto relativismo, ya que cada Estado no estaría ligado por el derecho internacional general oponible a todo sujeto internacional, sino por un cuerpo de reglas determinadas que él ha aceptado previamente.

57 Jennings, Robert, op. cit., pp. 72 y 73.

58 Rubin, Alfred P., op. cit., p. 15. 
Siguiendo la teoría positivista, una manifestación de voluntad o una determinada práctica estatal no puede dar origen a una norma más que cuando una norma superior lo ha dispuesto así. ${ }^{59}$ Nuestra labor será encontrar en qué norma superior se encuentran fundamentados los actos unilaterales de los Estados, lo cual analizaremos a continuación.

\section{A. Acta sunt servanda y pacta sunt servanda}

Un acto, según las partes que intervienen en su emisión, puede ser unilateral o plurilateral. Un pacto necesariamente es plurilateral, ya que implica el consenso entre dos o más partes.

Por lo tanto, el principio de pacta sunt servanda, ${ }^{60}$ fundamento de los tratados, sólo es aplicable en situaciones consensuales, es decir, acuerdo entre dos o más Estados. La insistencia en insertar a los actos jurídicos unilaterales dentro del derecho convencional, fundamentándolos en este principio probablemente sea consecuencia de la aproximación que existe entre estos actos y la "estipulación a favor de terceros", ${ }^{61}$ que aunque ambas tienen el mismo efecto (generar una obligación al emisor y su correspondiente derecho a un tercer Estado sin necesidad de su consentimiento), la estipulación se inserta dentro del marco convencional: sus efectos se producen y es oponible a partir de que el tratado entra en vigor, y si el tratado se da por terminado, la estipulación también, ya que ésta no tiene vida independiente del tratado.

Se puede afirmar de modo general que el hecho de que no exista consenso para la creación y producción de efectos jurídicos de los actos jurídicos unilaterales de los Estados impide la aplicación de la norma pacta sunt servanda. Goodman va un poco más allá: además de sostener que el fundamento de estos actos es la norma pacta sunt servanda, pro-

59 Kelsen, Hans, Teoría pura del derecho, 12a. ed., México, Porrúa, 2002.

60 Expresión latina que quiere decir "lo pactado obliga".

${ }^{61}$ La estipulación a favor de terceros es la disposición de un tratado que conlleva una promesa en beneficio de un sujeto de derecho internacional que no es parte del tratado. Queda establecida en el artículo 36, inciso 1, de la Convención de Viena sobre el Derecho de los Tratados. 
pone que se modifique a acta sunt servanda para que se distinga entre convencional y lo unilateral, en pro de la seguridad y armonía de las relaciones internacionales. ${ }^{62}$ Pero una cosa es buscar el mantenimiento y funcionamiento del sistema internacional, y otra es el modificar las normas ya establecidas de modo que comprendan más allá de su significado. En todo caso es asentar, sin fundamento alguno, principios de derecho. Esto no parece ser evidente, ya que también autores como Mulamba ${ }^{63}$ y Barsalou ${ }^{64}$ consideran que este "nuevo principio" — aunque remonten su existencia al origen de la sociedad internacional — es su fundamento.

Podemos hacer esta afirmación, sobre todo por el hecho que desde los primeros estudios de parte de la Comisión de Derecho Internacional se sostiene la irrelevancia de crear un principio, cualquiera que sea, para fundamentar los actos unilaterales, incluyendo expresamente acta sunt servanda, promissio est servanda y declaratio est servanda. ${ }^{65}$

\section{B. Buenafe}

Por "buena fe" no se está invocando a la confianza de terceros Estados en la palabra del emisor (apelando a un sentido subjetivo), sino a la confianza que pueden tener en el carácter obligatorio del acto jurídico en general, ya sea por el cumplimiento voluntario del emisor, o por el funcionamiento de mecanismos de responsabilidad internacional (que es un sentido objetivo). Es cierto que no es lo ideal en el ámbito internacional exigir el cumplimiento forzoso, pero responde a necesidades

62 Goodman, Camille, op. cit., p. 67.

63 Mulamba, Mbuyi, Introduction a l'étude des sources modernes du droit international public, Bruselas, Bruylant, 1999, pp. 153-164.

64 Barsalou, Olivier, op. cit., pp. 395-420.

65 Asamblea General de la ONU, "Informe de la Comisión de Derecho Internacional sobre la labor realizada en su 50o. periodo de sesiones”, Documento oficial A/53/10, Suplemento núm. 10, 1998, párr. 150. Cabe aclarar que en el primer informe del relator especial sobre los actos unilaterales de los Estados (Documento oficial A/CN.4/486, 5 de marzo de 1998, párr. 157), sí se consideró la aplicación de acta sunt servanda para la promesa, renuncia y reconocimiento, pero para el caso de la protesta, se afirmó que su fundamento estaba en la buena fe. Desconocemos la razón de esta distinción ya que no se precisa alguna. 
reales, y como dice Sicault: éste es el precio de la seguridad en las relaciones internacionales. ${ }^{66}$

El principio de buena fe fue declarado, por la resolución 2625 (XXV) de la Asamblea General de la ONU, ${ }^{67}$ como uno de los principios constitucionales del ordenamiento internacional de nuestro días.

Charpentier considera a la buena fe, no como fundamento del nacimiento de la obligación, sino de su ejecución. ${ }^{68}$ Es una sutil diferencia, pero con implicaciones importantes. Se centra en que la obligación debe ser cumplida de buena fe, viéndose entonces forzado a la estabilidad de las relaciones internacionales como fundamento de la creación de la obligación, ${ }^{69}$ apelando con ello a una explicación metajurídica, haciendo así un razonamiento falaz y saliendo del campo estrictamente jurídico, por lo que su explicación debe ser desechada.

Charpentier además, sostiene que los Estados se abstendrán de violar su obligación, no por temor a la responsabilidad que se pueda derivar de dicha violación, sino por el temor a que terceros Estados pierdan la confianza en él. ${ }^{70} \mathrm{Si}$ esto fuera así, no hubiese habido necesidad de crear convenciones en materia de responsabilidad, ni tampoco de instaurar tribunales internacionales. Aún más, habría unidad entre lo político y lo jurídico. Debemos desechar su argumento por razones históricas, jurídicas y políticas.

Surge, sin embargo, una objeción razonable: el sostener que la buena fe no es un adecuado fundamento para los actos jurídicos unilaterales ya que el principio está demasiado adentrado en el terreno moral, careciendo de significado jurídico preciso y autónomo. Zoller incluso sostiene que estaríamos ante una moralización progresiva del derecho internacional, dando pasos atrás a la búsqueda de enajenarlo del dere-

66 Sicault, Jean Didier, op. cit., p. 684.

${ }^{67}$ Asamblea General de la ONU, Declaración sobre los principios de Derecho Internacional referente a las relaciones de amistad y a la cooperación entre los Estados de conformidad con la Carta de las Naciones Unidas, resolución 2625 (XXV) del 24 de octubre de 1970.

${ }_{68}$ Charpentier, Jean, "Engagements unilatéraux et engagements conventionnels: différences et convergences”, Theory of International Law at the Threshold of the 21st Century : Essays in Honor of Krzysztof Skubiszewski, Kluwer Law International, La Haya, 1991, p. 373.

69 Ibidem, p. 374.

70 Ibidem, p. 378. 
cho natural. ${ }^{71}$ Pero si este razonamiento es preciso, entonces no se podría aplicar la buena fe al derecho de los tratados, ${ }^{72} \mathrm{ni}$ a la regla de pacta sunt servanda de modo general, ni tampoco a las obligaciones derivadas de la Carta de la ONU. ${ }^{73}$ Si tomamos en cuenta las declaraciones de la Asamblea General y de la Comisión de Derecho Internacional, debemos desechar este argumento.

Es un principio jurídico, y de eso no hay duda. Para reforzar nuestra posición, se hace imperioso el apelar a la jurisprudencia internacional. Recurrimos a una afirmación de la Corte Internacional de Justicia:

Uno de los principios básicos que rigen la creación y ejecución de obligaciones jurídicas, sea cual sea su fuente, es el principio de buena fe. La confianza es inherente a la cooperación internacional, particularmente en una época en la que esta cooperación se vuelve cada vez más esencial en diversas materias. ${ }^{74}$

\section{LA PRÁCTICA INTERNACIONAL}

Corresponde ahora analizar la práctica internacional a partir de la definición y caracterización hecha en los apartados anteriores. Determinaremos si dicha práctica en realidad constituye un genuino acto jurídico unilateral o se encuadra en distintas figuras jurídicas.

\section{Tipología}

La más amplia tipología de actos jurídicos unilaterales de los Estados que existe en esta materia, comprende diversas prácticas tales como la

71 Zoller, E., La bonne foi en droit international public, París, Pedone, 1977, pp. 353-354, apud Sicault, op. cit., p. 680.

72 Artículo 26 de la Convención de Viena sobre el Derecho de los Tratados.

73 Artículo 2o. de la Carta de las Naciones Unidas.

${ }^{74}$ Nuclear tests, op. cit., párr. 46, traducción propia, en inglés: One of the basic principles governing the creation and performance of legal obligations, whatever their source, is the principle of good faith. Trust and confidence are inherent in international co-operation, in particular in an age when this co-operation in many fields is becoming increasingly essential. 
promesa, la renuncia, la protesta, el reconocimiento y la notificación. Por ejemplo, mientras que Brownlie incluye exclusivamente a la protesta, la promesa, la renuncia y el reconocimiento en su estudio de los actos jurídicos unilaterales de los Estados, ${ }^{75}$ Bondia y Suy, en adición a los tipos estudiados por Brownlie, incluyen además la notificación. ${ }^{76}$

Es importante señalar que en la práctica internacional, salvo el de la promesa, no son frecuentes los ejemplos de cada tipo. Esta circunstancia no es, en modo alguno, razón para una omisión teórica, ya que la importancia de analizar la tipología radica en permitir actuar ante situaciones no previstas, dando mayor seguridad jurídica y estabilidad a las relaciones internacionales.

\section{A. Promesa}

La promesa es el compromiso formulado por un sujeto de derecho internacional que ofrece un cierto comportamiento de hacer o de no hacer respecto de otro sujeto. ${ }^{77}$ No estimamos que haya razones por las que no se pueda considerar que la promesa también recaiga sobre obligaciones de dar, tratándose de cualquier bien propiedad del Estado en cuestión (como podría ser el regalar una construcción para la instalación de su misión diplomática).

La práctica internacional respecto a promesas realizadas por el Estado son tan diversas que provoca confusiones entre los más altos doctrinarios cuando se trata de ejemplificar esta figura. ${ }^{78}$ Los autores, in-

75 Brownlie, Ian, op.cit., p. 612

76 Bondia García, David, Régimen jurídico de los actos unilaterales de los Estados, Barcelona, J. M. Bosch Editor, 2004, p. 83; Suy, Eric, Les actes juridiques unilatéraux en droit International public, París, Librairie Générale de Droit et Jurisprudence, 1962, p. 43

77 Castillo, Lilian del, "Comentarios sobre el derecho internacional de los actos jurídicos unilaterales", Estudios de derecho internacional en homenaje del profesor Ernesto J. Rey Caro, Córdoba, Lerner, 2002, vol. 1, pp. 32 y 33.

78 Como ejemplos de aparentes promesas unilaterales, en Legal Status of Eastern Greenland (Dinamarca c. Noruega), CPIJ, Serie A/B, núm. 53, sentencia del 5 de abril de 1933, no se cuestiona el hecho de que la declaración hecha por el señor Ihlen, el ministro de asuntos exteriores de Noruega, en el sentido de que su gobierno no pondría obstáculos a los planes del gobierno danés de extender su soberanía a todo el territorio de Groenlandia, tenga carácter obligatorio. Pero la sentencia de la Corte no especifica si esta obligación tiene un carácter bilateral o unilateral. Formalmente se trata de una expresión de voluntad de una represen- 
terpretando de manera distinta un número limitado de precedentes, llegan a conclusiones opuestas sobre la existencia y fuerza jurídica de las promesas unilaterales. ${ }^{79}$

Las formas de relacionarse internacionalmente son tan ricas y variadas, que es fácilmente concebible que un Estado encuentre pertinente para sus propios intereses el asumir obligaciones unilateralmente, en lugar de entablar negociaciones con otros Estados para celebrar un tratado o esperar la consolidación de una norma consuetudinaria.

\section{B. Renuncia}

La renuncia es una expresión unilateral de voluntad de retirar un derecho, una facultad, una pretensión o una reclamación de su patrimonio. ${ }^{80}$ Sicault sostiene que existen dos formas de actos unilaterales: los positivos (obligaciones de hacer) y los negativos (obligaciones de no hacer). Pero elimina a la renuncia de su estudio, diciendo que los actos unila-

tante del gobierno noruego capaz de comprometerlo en la esfera internacional, pero desde el punto de vista del fondo, se trata de una respuesta a una solicitud de un representante de otro gobierno. La oferta de Dinamarca y la aceptación de Noruega, constituyen un vínculo contractual y no unilateral, a pesar de que no se trate de una relación quid pro quo. Muchos autores también consideran la declaración de Egipto de 1957 sobre el canal de Suez, en la que este gobierno se compromete a respetar las disposiciones y el espíritu de la Convención de Constantinopla de 1888 sobre el uso libre y pacífico del canal. En este caso, no se trata de obligaciones nuevas, sino de una simple confirmación de obligaciones convencionales. El hecho de que esta declaración se haya registrado ante la Secretaría General de la ONU debe ser entendida como parte integrante de estos convenios internacionales, y no como un acto jurídico unilateral. Por otro lado, sí constituyen auténticas promesas, el caso de Nuclear tests, op. cit., en el que las declaraciones hechas por el presidente, el ministro de relaciones exteriores, y el ministro de defensa sobre el final de los ensayos nucleares en el océano de parte del gobierno francés, son considerados por la CIJ como declaraciones oponibles ante terceros, por lo que queda sin objeto la demanda de Australia y Nueva Zelanda de que la Corte declare que Francia tenía dicha obligación. En este caso, Francia claramente se auto-restringió. Asimismo, la declaración del ministro de relaciones exteriores soviético, el señor Gromyko, prometió ante la Asamblea General de la ONU que su país no sería el primero en usar armas nucleares, agregando que "esta obligación entra en vigor inmediatamente en el momento en que es proclamada ante la Asamblea General”, siendo clara la intención de asumir una obligación jurídica mediante la realización de un acto jurídico unilateral.

79 Jacqué, Jean-Paul, “A propos de la promesse unilatérale”, Mélanges offerts à Paul Reuter: le droit international: unité et diversité, París, Pedone, 1981, p. 327.

80 Salmon, Jean, op. cit., p. 968. 
terales son un modo de crear una obligación, mientras que la renuncia es un modo de extinguirlas. ${ }^{81} \mathrm{~A}$ primera vista parece tener razón, pero su desacierto de apreciación es el pasar por alto que el objeto de la renuncia unilateral nunca puede ser una obligación, sino sólo un derecho disponible, es decir, un derecho que no sea necesario para la ejecución de un deber.

Para algunos autores, la renuncia sólo es un acto unilateral en cuanto a que se trataría de una promesa cuyo objeto es de no hacer. Del Castillo reconoce esta posibilidad cuando afirma que "la promesa de un determinado comportamiento puede ser el abandono de un derecho existente o la limitación de su alcance" ${ }^{82}$ Subsume la renuncia dentro de la promesa, siendo la primera no más que una especie de la segunda. Gattini esclarece este punto, al afirmar que "hay que distinguir entre la pérdida de un derecho como consecuencia de la renuncia, y la renuncia al derecho de hacerlo valer". ${ }^{83}$ En el primer caso estaríamos ante una auténtica renuncia, pero en el segundo sí se trata de una promesa de no hacer en un caso concreto. Gattini lo pone en palabras que no pueden ser superadas al sostener que "el decir que la renuncia es una promesa de no hacer valer un derecho, es erróneo, ya que la renuncia tiene por efecto la extinción de un derecho, mientras que la promesa conlleva una obligación hacia otro". ${ }^{84}$

Se debe hacer hincapié en que, al ser la promesa y la renuncia actos que limitan la libertad y soberanía de los Estados, dado que implican la disminución de sus derechos — ya sea por la ampliación de sus obligaciones, o por la reducción de sus derechos_- estas figuras siempre deben ser expresas, y nunca pueden presumirse. ${ }^{85}$

\section{Protesta}

La protesta es el acto por el cual uno o varios sujetos de derecho internacional manifiestan su voluntad de no reconocer la validez u opo-

81 Sicault, Jean Didier, op.cit., p. 639.

82 Castillo, Lilian del, op. cit., p. 30.

83 Gattini, Andrea, "La renonciation au droit d'invoquer la responsabilité", Völkerrecht als Wertordnung: Festschrift für Christian Tomushat, Kehl, Engel, 2006, pp. 326-327.

${ }^{84}$ Ibidem, p. 319.

${ }^{85}$ Lotus case, cit., p. 18. 
nibilidad de actos, conductas o pretensiones de terceros. ${ }^{86}$ La protesta no satisface las características definitorias establecidas en los capítulos anteriores, debido a que:

Por un lado, una de las características de la protesta es que es revocable a voluntad. Con ello, la protesta se vuelve por definición potestativa. Estaríamos entonces no frente a un compromiso jurídico, sino político.

Por otro lado, la protesta tiene por efecto el evitar que un derecho salga de la esfera patrimonial del Estado, o que entre una nueva obligación. Sin duda esto es un efecto jurídico, pero éste efecto de la protesta no modifica la esfera patrimonial del Estado emisor del acto, sino que la conserva.

Finalmente, para que la protesta produzca efectos (y por lo tanto sea un acto unilateral stricto sensu) debe ser reiterada. Exigiendo una prolongación en el tiempo de la protesta se desvirtúa su carácter de autónoma y de surtir efectos por sí misma, al requerirse una multiplicidad de actos. Por lo que una protesta realizada de modo aislado y único difícilmente puede producir efectos jurídicos en el plano internacional.

\section{Reconocimiento}

El reconocimiento es el acto por medio del cual se verifica la existencia de un hecho, situación o pretensión creada o sostenida por otro, aceptando los efectos que se derivan de esa situación. ${ }^{87}$ Tradicionalmente se considera que la obligación de aquí derivada es la de respetar la modificación del orden jurídico internacional en la cual no se ha participado. ${ }^{88}$ Es un acto político que implica consecuencias jurídicas.

No hay duda de que es el acto con el mayor matiz político, ya que se da el reconocimiento a Estados, gobiernos, naciones, grupos beligerantes, movimientos de liberación nacional y naciones. ${ }^{89}$ La misma Carta de la Organización de Estados Americanos establece que el reconocimien-

\footnotetext{
86 Salmon, Jean, op. cit., p. 907.

87 Castillo, Lilian del, op. cit., p. 28.

88 Rigaldies, Francis, op. cit., p. 429.

89 Salmon, Jean, op. cit., pp. 942-944.
} 
to es simplemente una declaración, y no afecta de ninguna manera los derechos y obligaciones de cada Estado. ${ }^{90}$

\section{E. Notificación}

La notificación es una acción oficial realizada por un sujeto de derecho internacional con la finalidad de hacer un hecho, una situación, una acción o un documento, del conocimiento de otro actor internacional. ${ }^{91}$ En términos más simples, se trata de la forma de dar a conocer ciertos hechos o actos.

La notificación sólo es un medio para dar a conocer el acto jurídico, y no es un acto jurídico en sí. No debemos confundir la forma con el contenido.

\section{Evaluación crítica de la tipología}

A partir de lo anteriormente descrito, podemos distinguir, según la finalidad del acto, aquellos destinados a reaccionar ante una situación, una pretensión o un acto ya existente, ${ }^{92}$ como la protesta y el reconocimiento, de aquellos destinados a accionar o modificar directamente el orden jurídico, es decir la promesa y la renuncia. Sólo los segundos constituirían auténticos actos jurídicos unilaterales en sentido estricto, ya que los primeros carecerían del elemento de autonomía, al ser una reacción y no una acción.

Los únicos modos en los que el patrimonio jurídico del Estado y su libertad de acción se pueden ver limitado es si aumentan las obligaciones a su cargo (remitiéndonos a la promesa), o si disminuyen sus derechos (remitiéndonos a la renuncia). Por lo tanto, podemos concluir que tanto la renuncia como la promesa sí cumplen los requisitos necesarios para definirse como "actos jurídicos unilaterales", mientras que la pro-

90 Artículo 13 de la Carta de la Organización de Estados Americanos.

91 Salmon, Jean, op. cit., p. 758.

92 Los que Suy llama “actos adjuntos”, cfr. Suy, Eric, op. cit., p. 633. 
testa, el reconocimiento y la notificación carecen de algún elemento, el de autonomía, que impide clasificarlos como tales.

En este sentido, Degan lo formula en términos muy claros:

El reconocimiento, así como la protesta, son sólo una reacción a los actos o reivindicaciones de otros. Difícilmente pueden considerarse genuinas fuentes internacionales, creando derecho u obligaciones para su autor en cualquier circunstancia posible. ${ }^{93}$

La declaración no debe simplemente enunciar una situación ya existente, sino crear un nuevo estado de cosas, una nueva situación jurídica, por lo que son sólo la promesa y la renuncia las que cumplen con este requisito.

\section{CONCLUSIÓN}

Como quedó establecido, el acto jurídico unilateral del Estado es aquella actividad realizada por el Estado de modo individual y autónomo, que tiene como efecto la modificación de la esfera de obligaciones internacionales del sujeto emisor, ya sea en relación con uno o más sujetos de derecho internacional, o con la comunidad internacional en general, en razón de que dicha actividad se realiza justamente con la intención de producir efectos jurídicos.

Los actos jurídicos unilaterales de los Estados constituyen una auténtica fuente de obligación en el plano internacional, independiente de cualquier otro modo de producción normativa, tanto convencional como consuetudinaria. Dichas obligaciones se fundamentan en el principio de buena fe, reconocido como uno de los principios generales del derecho.

93 Degan, Vladimir-Djuro, op. cit., pp. 159-160, traducción propia, en inglés: Recognition, as well as protest, is only a reaction to other's claims or acts. It can scarcely be considered as a genuine international source, creating rights or obligations for their author in all possible circumstances. 
Es importante establecer un régimen jurídico claro en la materia, ya que los actos jurídicos unilaterales de los Estados son un complemento importante para el sistema internacional, indispensable cuando la negociación es imposible. La certidumbre en el régimen jurídico permitiría saber de antemano cuándo un Estado queda vinculado jurídicamente, y cuándo se trata de compromisos políticos. Esto evitaría el acudir ante instancias internacionales, dando mayor certeza jurídica, y mejorando las relaciones entre los Estados.

Son tres los puntos fundamentales a considerar como regulación de los actos jurídicos unilaterales de los Estados:

1) Los Estados pueden imponerse obligaciones a sí mismos o ejercer unilateralmente sus derechos dentro de los límites aceptados por el derecho internacional general.

2) Estos actos deben ser realizados por un sujeto capaz, con un objeto determinado y una expresión clara de la intención de obligarse jurídicamente.

3) Este acto puede cesar de producir efectos y extinguirse, a condición que no sea por causas arbitrarias, y siempre y cuando la obligación derivada no adquiera la calidad de potestativa.

Los actos jurídicos unilaterales de los Estados significan, en cuanto a la esfera patrimonial del sujeto emisor, o bien una disminución de sus derechos, o bien un aumento de sus obligaciones, ya sea frente a uno o más sujeto de derecho internacional, o frente a la comunidad internacional en general. Esto se traduce como la formulación de renuncias o como la formulación de promesas. En realización de una renuncia, el Estado estaría sustrayendo de su esfera jurídica un derecho. Por medio de la promesa, estaría adquiriendo una nueva obligación.

La existencia de un régimen jurídico claro y consensuado sobre los actos jurídicos unilaterales de los Estados les permitiría ampliar sus posibilidades de actuación en el sistema internacional. Al darles mayor certeza jurídica se pueden prever las consecuencias jurídicas de sus actos unilaterales. A pesar de esta ventaja, se observa, tanto de los trabajos de la Comisión de Derecho Internacional, así como de textos de doctrinarios, una cierta resistencia de los Estados a que se establezca 
un régimen jurídico sobre estos actos ya que temen verse limitados en sus actuaciones al enfrentarse de modo inesperado a obligaciones jurídicas que no buscaron asumir. La comunidad internacional en general debe trabajar para mostrar a los Estados que un régimen jurídico claro sobre los actos jurídicos unilaterales ofrece mayores ventajas que inconvenientes.

Como dijo Antoine Loysel: ligamos a los bueyes por los cuernos, y a los hombres por sus palabras. Agrego: a los Estados por sus actos.

\section{BIBLIOGRAFÍA}

BARSALOU, Olivier, "Les actes unilatéraux étatiques en droit International public: observations sur quelques incertitudes théoriques et pratiques", The Canadian Yearbook of International Law, Vancouver, University of British Columbia Press, vol. 44, 2006.

BISHOP, William, "General Course of Public International Law", Recueil des Cours de l'Academie de Droit International, La Haya, Nijhoff, 1965, t. 115.

BOndia García, David, Régimen jurídico de los actos unilaterales de los Estados, Barcelona, J. M. Bosch Editor, 2004.

BowetT, D. W., "Estoppel Before International Tribunal and its Relation to Acquiescence", British Yearbook of International Law, Oxford, Oxford University Press, 1957.

Brown, Christopher, "A Comparative and Critical Assessment of Estoppel in International Law”, University of Miami Law Review, University of Miami Law School, Coral Gables, vol. 50, 1996.

Brownlie, Ian, Principles of Public International Law, 6a. ed., Oxford, Nueva York, 2003.

Castillo, Lilian del, "Comentarios sobre el derechointernacional de los actos jurídicos unilaterales”, Estudios de derecho internacional en homenaje del profesor Ernesto J. Rey Caro, Córdoba, Lerner, 2002, vol. 1.

CHARPENTIER, Jean, "Engagements unilatéraux et engagements conventionnels: différences et convergences", Theory of International Law at the Threshold of the 21st Century: Essays in Honor of Krzysztof Skubiszewski, La Haya, Kluwer Law International, 1991. 
D’ Aspermont Lynden, Jean, "Les travaux de la Commission de Droit International relatifs aux actes unilatéraux des Etats”, Revue Générale de Droit International Public, París, Pedone, vol. 109, fasc. 1, 2005.

Degan, Vladimir-Djuro, "Unilateral Acts as a Source of Particular International Law”, The Finnish Yearbook of International Law, Helsinki, Helsinki University Press, vol. 5.

DieZ De Velasco, Manuel, Instituciones de derecho internacional público, 12a. ed., Madrid, Tecnos, 1999.

Dordi, Claudio, “Are GATTs Schedules of Concessions Similar to Unilateral Acts?", WTO law and process: proceedings of the 2005 and 2006 AnnualWTO Conference, Londres, British Institute of International and Comparative Law, 2007.

FAUVARQUe-Cosson, Bénédicte, "La confiance légitime et l'estoppel: rapport général”, La confiance légitime et l'estoppel, París, Société de Legislation Comparée, 2007.

Fitzmaurice, Sir Gerald G., "Some Problems Regarding the Formal Sources of International Law", Symbolae Verzijl: présentées au professeur J. H.W.Verzijl à l'occasion de son LXX-ième anniversaire, La Haya, Nijhoff, 1958.

FRANCE TNP 2010, Turning commitments into actions, The NPT: our vital instrument for our collective security, http: / / www. francetnp2010.fr/ spip.php?rubrique45, fecha de consulta: 12 de agosto de 2010.

GAILlARD, Emmanuel, "L'interdiction de se contredire en détriment d'autrui comme principe général du droit du commerce international : le principe de l'estoppel dans quelques sentences arbitrales récentes", Revue de l'Arbitrage: Bulletin de Comité Français de l'Arbitrage, París, 1985.

GATTINI, Andrea, "La renonciation au droit d'invoquer la responsabilité", Völkerrecht als Wertordnung: Festschrift für Christian Tomushat, Kehl, Engel, 2006.

GonzÁlez CAmpos, Julio D. et al., Curso de derecho internacional público, Oviedo, Universidad de Oviedo, 1983, vol. I.

Goodman, Camille, "Acta Sunt Servanda?: A Regime for Regulating the Unilateral Acts of States at International Law", The Australian Yearbook of International Law: Annual Survey of Current problems of public and private International law with a digest of Australian practice, Sydney, Butterworths, 2004, vol. 24. 
Horchani, Ferhat, Les sources du droit International public, 10a. ed., París, Librairie General de Droit et Jurisprudence, 2008.

JACQUÉ, Jean-Paul, “A propos de la promesse unilatérale”, Mélanges offerts à Paul Reuter: le droit international : unité et diversité, París, Pedone, 1981.

JENniNGS, Robert, "What is International Law and How Do We Tell When We See it?", Schweizerisches Jahrbuch für internationales Rechts, Zürich, 1981, vol. 37.

Kelsen, Hans, Teoría Pura del Derecho, 12a. ed., México, Porrúa, 2002.

KyRIAKOPOUlos, Georges D., Les actes unilatéraux des Etats: essai sur la théorie et la pratique internationale, Bruselas, Bruylant, 2008.

Manero Salvador, Ana, "Hacia una definición de acto unilateral del Estado”, International Law: Revista Colombiana de Derecho Internacional, Bogotá, núm. 9, mayo de 2007, pp. 453-489.

Miaja DE LA MuEla, Adolf, "Los actos unilaterales en las relaciones internacionales”, Revista Española de Derecho Internacional, Madrid, vol. 20, 1967.

Mulamba, Mbuyi, Introduction a l'étude des sources modernes du droit international public, Bruselas, Bruylant, 1999.

MüLlERSON, Rein, "The Interplay of Objective and Subjective Elements in Customary Law", International Law:Theory and Practice: Essays in Honour of Eric Suy, La Haya, Nijhoff, 1998, pp. 161-178.

NoCKer, Thomas y French, Gregory, "Estoppel: What's the Government's Word Worth? An Analysis of German Law, Common Law Jurisdictions, and of the Practice of International Arbitral Tribunals", The International Lawyer, Washington D.C., ABA, vol. 24, núm. 2, 1990, pp. 409-437.

NTI Working for a safer world, Negative Security Assurances and Positive Security Assurances, Declaración del embajador Stephen J. Ledogar, http://www.nti.org/db/china/npsaorg.htm, fecha de consulta: 29 de noviembre de 2010.

ODENDAHL, Kerstin, "Les sources du droit international public et l'evolution de leurs modes de formation”, Les sources du droit: aspects contemporains, París, Centre d'Etudes du Monde Arabe, 2007, pp. 163-177.

PASTOR Ridruejo, José A., Curso de derecho internacional público y organizaciones internacionales, 14a. ed., Madrid, Tecnos, 2010. 
Pecourt García, Enrique, "El principio del estoppel en derecho internacional público", Revista Española de Derecho Internacional, Madrid, 1962.

Puente EgIdo, J., Casos prácticos de derecho internacional público, 3a. ed., Madrid, EDISOFER, 2001.

Quoc Dinh, Nguyen, Droit International Public, 5a. ed., París, Librairie Générale de Droit et de Jurisprudence, 1994.

Real Academia Española, Diccionario de la lengua española, 22a. ed., www.rae.es, fecha de consulta: 29 de noviembre de 2010.

Rico Álvarez, Fausto y Garza BANDAla, Patricio, Teoría general de las obligaciones, 2a. ed., México, Porrúa, 2006.

RIGALDIES, Francis, “Contribution a l'étude de l'acte juridique unilatéral en Droit International Public", La revue juridique Thémis de l'Université de Montréal, Montréal, Centre de Recherche en Droit Public, vol. 15, 1980-1981.

RODRÍGUEZ CEDEÑo, Víctor, "De la interpretación y revocación de los actos unilaterales en sentido estricto”, Anuario Colombiano de Derecho Internacional, Bogotá, año I, núm. 1, 2008.

y Guerrero Peniche, Nicolás, "Los actos unilaterales de los Estados en derecho internacional: los trabajos de codificación de la comisión de derecho internacional", Anuario Mexicano de Derecho Internacional, vol. III, 2003, pp. 195-223.

y Torres Cazorla, Ma. Isabel, "Contribución al estudio de los actos unilaterales de los Estados: ¿una labor de codificación posible?", Liber amicorum en homenaje al profesor Dr. Didier Opertti Badan, Montevideo, Fundación Cultura Universitaria, 2005.

RuBIN, Alfred P., "The International legal effects of unilateral declarations", The American Journal of International Law, Washington D. C., American Society of International Law, vol. 71, 1977.

SAlmon, Jean, Dictionnaire de droit international public, Bruylant, Bruselas, 2001.

SANTULli, Carlo, "Travaux de la Comisision du droit international”, Annuaire français de droit international, vol. 49, 2003.

SCHACHTER, Oscar, "Towards a theory of international obligation”, Schweizerisches Jahrbuch für internationales Rechts, Zürich, vol. 37, 1981. SEARA VAZQUeZ, Modesto, Derecho internacional público, 22a. ed., México, Porrúa, 2005. 
SELLARÉS Serra, Jordi, Applause as a Unilateral Act (Is an image worth a thousand words?), European Society of International Law, 2006, http:// www.esil-sedi.eu/publi_search.php, fecha de consulta: 26 de noviembre de 2010.

SinCLAIR, Ian, "Estoppel and Acquiescence", Fifty years of the International Court of Justice: Essays in Honour of Sir Robert Jennings, Cambridge, Cambridge University Press, 1996.

SICAULT, Jean Didier, "Du caractère obligatoire des engagements unilatéraux en droit international public“, Revue Générale de Droit International Public, París, Pedone, vol. 83, 1979.

SKuBISZEWSKI, Krzysztof, "Les actes unilatéraux des Etats”, Droit international: bilan et perspectives, París, Pedone, 1991, pp. 231-251.

SuY, Eric, Les actes juridiques unilatéraux en droit International public, París, Librairie Générale de Droit et Jurisprudence, 1962.

, "Unilateral Acts of States as a Source of International Law: Some New Thoughts and Frustrations", Droit du pouvoir, pouvoir du droit: mélanges offerts a Jean Salmon, Bruselas, Bruylant, 2007.

Time, Top 10 U.N General-Assembly Moments, Khruschev loses his cool, http: / / www.time.com / time / specials / packages / article/0, 28804,18435 06_1843505_1843496,00.html, fecha de consulta: 12 de agosto de 2010.

Torres Cazorla, Ma. Isabel, "La Historia jamás contada de los actos unilaterales de los Estados: de los Ensayos Nucleares al asunto de la República Democrática del Congo contra Ruanda”, Revista española de derecho internacional, Instituto Francisco de Vitoria, Madrid, vol. 58, núm. 1, 2006.

United States Commission on Ocean Policy, Presidential Proclamation No. 2667, Policy of the United States with respect to the natural resources of the subsoil and sea bed of the continental shelf, http: / /oceancommis sion.gov/documents/gov_oceans/truman.pdf, fecha de consulta: 13 de agosto de 2010 .

Venturini, Gian Carlo, “La portée et les effets juridiques des attitudes et des actes unilatéraux des Etats“, Recueil des Cours de l'Academie de Droit International, La Haya, Nijhoff, t. 112, 1964.

Verdross, Alfred, Derecho Internacional Público, Aguilar, Madrid, 1978.

VIRALLY, Michel, "Les actes unilatéraux des organisations internationales“, Droit international: bilan et perspectives, París, Pedone, 1991. 
Weingerl, Ales, Definition of Unilateral Acts of States, International Law Doctrines, European Society of International Law, 2004, http: / /www. esil-sedi.eu/publi_search.php, fecha de consulta: 26 de octubre de 2010.

ZemaneK, Karl, "Unilateral Legal Acts Revisited”, International Law: Theory and Practice: Essays in Honour of Eric Suy, La Haya, Nijhoff, 1998, pp. 209-221.

Legislación consultada

Instrumentos internacionales

Organización de Estados Americanos, Convención sobre derechos y deberes de los Estados, firmada en Montevideo, Uruguay, el 26 de diciembre de 1933, Diario Oficial de la Federación, 21 de abril de 1936.

, Carta de la Organización de Estados Americanos, firmada en Bogotá, Colombia, el 30 de abril de 1948, Diario Oficial de la Federación, 13 de enero de 1949.

Organización de las Naciones Unidas, Estatuto de la Corte Internacional de Justicia, anexo a la Carta de Naciones Unidas, San Francisco, Estados Unidos de América, 26 de junio de 1945, Diario Oficial de la Federación, 17 de octubre de 1945.

, Convención de Viena sobre el Derecho de los Tratados, Viena, Austria, 23 de mayo de 1969, Diario Oficial de la Federación, 14 de febrero de 1975.

, Convención de las Naciones Unidas sobre el Derecho del Mar, Montego Bay, Jamaica, 10 de diciembre de 1982, Diario Oficial de la Federación, 1o. de junio de 1983.

, Manual de Tratados, Sección de Tratados de la Oficina de Asuntos Jurídicos, 2001, http://untreaty.un.org/English/TreatyHandbookSp an.pdf, fecha de consulta: 24 de agosto de 2010.

Proyecto de Convención sobre Responsabilidad del Estado por hechos internacionalmente ilícitos, adoptado por la Asamblea General en la resolución 56/83 del 12 de diciembre de 2001, en http://untreaty. un.org/ilc/texts/instruments/english/draft\%20articles/9_6_2001.pdf. 
Asamblea General de la ONU, Declaración sobre los principios de Derecho Internacional referente a las relaciones de amistad y a la cooperación entre los Estados de conformidad con la Carta de las Naciones Unidas, Resolución 2625 (XXV) del 24 de octubre de 1970.

Asamblea General de la ONU, "Informe de la Comisión de Derecho Internacional sobre la labor realizada en su $48^{\circ}$ periodo de sesiones”, Documento oficial A/51/10, Suplemento núm. 10, 1996.

, "Informe de la Comisión de Derecho Internacional sobre la labor realizada en su 490. periodo de sesiones”, Documento oficial A/52/10, Suplemento núm. 10, 1997.

, "Informe de la Comisión de Derecho Internacional sobre la labor realizada en su 50o. periodo de sesiones”, Documento oficial A/53/10, Suplemento núm. 10, 1998.

, "Informe de la Comisión de Derecho Internacional sobre la labor realizada en su 510. periodo de sesiones”, Documento oficial A/54/10, Suplemento núm.10, 1999.

, "Informe de la Comisión de Derecho Internacional sobre la labor realizada en su 520. periodo de sesiones”, Documento oficial A/55/10, Suplemento núm. 10, 2000.

, "Actos unilaterales de los Estados: Respuesta de los gobiernos al cuestionario", Documento oficial A/CN.4/511, 6 de julio del 2000 .

Asamblea General de la ONU, "Principios rectores aplicables a las declaraciones unilaterales de los Estados capaces de crear obligaciones jurídicas”, Anuario de la CDI, Documento oficial A /61 / 10, 2006, Vol. II, Parte 2.

Rodríguez Cedeño, Víctor, "Primer informe sobre los actos unilaterales de los Estados", Documento oficial A/CN.4/486, 5 de marzo de 1998, en http://untreaty.un.org/ilc/guide/9_9.htm, fecha de consulta: 1 o. de diciembre de 2010.

, "Segundo informe sobre los actos unilaterales de los Estados", Documento oficial A/CN.4/500, 14 de abril de 1999, en http: / / untreaty.un.org/ilc/guide/9_9.htm, fecha de consulta: 1o. de diciembre de 2010 .

, "Tercer informe sobre los actos unilaterales de los Estados", Documento oficial A/CN.4/505, 17 de febrero de 2000, en http:/ / 
untreaty.un.org/ilc/guide/9_9.htm, fecha de consulta: 1o. de diciembre de 2010.

, "Cuarto informe sobre los actos unilaterales de los Estados", Documento oficial A/CN.4/519, 30 de mayo de 2001, en http: / untreaty.un.org/ilc/guide/9_9.htm, fecha de consulta: 1o. de diciembre de 2010.

Rodríguez Cedeño, Víctor, "Quinto informe sobre los actos unilaterales de los Estados", Documento oficial A/CN.4/525/Add.1, 17 de abril del 2002, en http://untreaty.un.org/ilc/guide/9_9.htm, fecha de consulta: 1o. de diciembre de 2010.

\section{Jurisprudencias}

Corte Europea de Derechos Humanos, Murat Akman c. Turquía, núm. 37453/97, sentencia del 26 de junio de 2001.

Corte Permanente de Justicia Internacional

Wimbledon case (Reino Unido, Francia, Italia y Japón c. Polonia), CPJI, Serie A, núm. 1, sentencia del 17 de agosto de 1923.

Lotus case (Francia c. Turquía), CPIJ, Serie A, núm. 10, sentencia del 7 de septiembre de 1927.

Legal Status of Eastern Greenland (Dinamarca c. Noruega), CPIJ, Serie A/B, núm. 53, sentencia del 5 de abril de 1933.

\section{Corte Internacional de Justicia}

Fisheries (Reino Unido c. Noruega), ICJ Reports 1951, sentencia del 18 de diciembre de 1951.

Certain Norwegians Loans (Francia c. Noruega), opinión individual del juez Sir Hersch Lauterpacht, ICJ Reports, 1957, sentencia del 6 de Julio de 1957.

Right of Passage over Indian Territory (Portugal c. India), excepciones preliminaries, ICJ Reports 1957, sentencia del 26 de noviembre de 1957. Arbitral Award made by the King of Spain on 23 December 1906 (Honduras c. Nicaragua), ICJ Reports 1960, sentencia del 18 de noviembre de 1960 . 
Temple of Preah Vihear (Cambodia c. Tailandia), fondo del asunto, ICJ Reports 1962, sentencia del 15 de junio de 1962.

Temple of Preah Vihear (Cambodia c. Tailandia), opinión individual del juez Sir Gerald Fitzmaurice, ICJ Reports 1962, sentencia del 15 de junio de 1962.

Barcelona Traction (Bélgica c. España), excepciones preliminares, ICJ Reports 1964, sentencia del 24 de julio de 1964.

North Sea Continental Shelf (República Federal de Alemania c. Países Bajos y Dinamarca), ICJ Reports 1969, sentencia del 20 de febrero de 1969. Nuclear Tests (Australia c. Francia), opinión disidente del juez Castro, ICJ Reports, 1974, sentencia del 20 de diciembre de 1974.

Delimitation of the Maritime Boundary in the Gulf of Maine Area (Canada c. Estados Unidos de América), sentencia del 12 octubre 1984, ICJ Reports 1984.

Military and Paramilitary Activities in and against Nicaragua (Nicaragua c. Estados Unidos de América), excepciones preliminares, ICJ Reports 1984, sentencia del 26 de noviembre de 1984.

Military and Paramilitary Activities in and against Nicaragua (Nicaragua c. Estados Unidos de América), fondo del asunto, ICJ Reports 1986, sentencia del 27 de junio de 1986.

Frontier Dispute (Burkina Faso c. Mali), ICJ Reports 1986, sentencia del 22 de diciembre de 1986.

Elettronica Sicula S.p.A. (ELSI) (Estados Unidos de América c. Italia), ICJ Reports 1989, sentencia del 20 de julio de 1989.

Armed Activities on the Territories of the Congo (New Application: 2002) (República democrática del Congo c. Ruanda), competencia y admisibilidad, ICJ Reports 2006, sentencia del 3 de febrero de 2006.

Territorial and maritime dispute (Nicaragua c. Colombia), excepciones preliminares, ICJ Reports 2007, sentencia del 13 de diciembre de 2007. 